\title{
Efficacy of amaranth sorghum grains porridge in rehabilitating moderately acute malnourished children in a low-resource setting in Kenya: A randomized controlled trial
}

\author{
Okoth $\mathrm{JK}^{1 *}$, Ochola $\mathrm{S}^{2}$, Gikonyo $\mathrm{NK}^{3}$ and Makokha $\mathrm{AO}^{1}$ \\ ${ }^{1}$ Department of Food Science and Technology, Jomo Kenyatta University of Agriculture and Technology, Nairobi, Kenya \\ ${ }^{2}$ Department of Food, Nutrition and Dietetics, Kenyatta University, Nairobi, Kenya \\ ${ }^{3}$ Department of Pharmacy and Complementary/Alt Medicine, Kenyatta University, Nairobi, Kenya
}

\begin{abstract}
In Kenya, wasting levels among children under five years reduced between 2010 (7\%) and 2014 (4\%), but the number of wasted children is still high. Thin porridge, mainly from cereals and starchy tubers is a popular complementary food, though inadequate for children`s nutritional requirements. It is low in energy, nutrient density and high in antinutrients. Traditionally, fortified blended foods such as corn-soy blend has been used to treat moderately acutely malnourished (MAM) children with limited effectiveness due to its low nutritive profile and relatively high level of anti-nutrients. Therefore nutrient-dense complementary foods are needed. This study aimed to determine the efficacy of amaranth sorghum grains product in rehabilitating MAM children. Villages in Kiandutu slums, were randomly assigned to two study groups; Treatment (TG) and control (CG). Mothers and their moderately malnourished children (6-23 months old) were recruited at a health centre and assigned to groups depending on their village of residence. Children in TG received germinated amaranth sorghum grains flour, those in CG received a blend of sorghum and maize grains flour, for a maximum period of 6 months. Each month, children`s morbidity status and anthropometric measurements were taken. The primary outcome was nutritional status judged by wasting. At baseline the groups' characteristics were similar. At month 5, 35.3\% and $12.9 \%$ of children in CG and TG were wasted respectively (Relative Risk [RR] RR=1.35 (95\% CI: 1.03-1.77; p=0.030) and at month 6, 62.1\% and $15.6 \%$ of the children CG and TG were wasted respectively RR=2.23 [( $95 \% \mathrm{CI}: 37-3.61 ; \mathrm{p}<0.001)$. Germinated amaranth sorghum grains may offer an alternative to treatment of MAM children. Nonetheless, it took longer than WHO recommended 90 days for rehabilitation of MAM children.
\end{abstract}

\section{Introduction}

In Kenya $4 \%, 26 \%$ and $11 \%$ of children under five are wasted, stunted and underweight respectively [1]. Poor quality complementary foods with low nutrient density and inappropriate feeding practices are among the major causes of malnutrition in young children [2]. In sub Saharan Africa moderately wasted children are treated with cornsoy blended flour (CSB) through targeted supplementary feeding programmes. However there have been doubts on the effectiveness of CSB in treating malnutrition $[3,4]$.

Ready to use therapeutic food (RUTF) has also been used to treat moderate acute malnutrition (MAM) [3,5]. However, milk in RUTF (25-35\% w/w) makes them too expensive for sustainable use in resource-poor settings. Also, the high nutrient concentration in RUTF may make them unsafe for MAM children. It has been suggested that lipid-based ready to use foods could prevent/treat MAM [4]. There is concern that MAM children may be susceptible to immunological reactions since their immune system is intact [4]. Therefore, there is a need for alternative nutrient dense foods that are affordable by most families that could prevent undernourishment.

Amaranth grain has a higher nutrient content compared to staple cereals $[6,7]$. It was complemented with sorghum in this study. Sorghum is drought tolerant and its nutritional profile is comparable to that of maize $[8,9]$. The study, aimed at evaluating the efficacy of amaranth sorghum grains product in improving the nutritional status of MAM children. It determined the study population`s demographic and socioeconomic characteristics, compared morbidity prevalence among the subjects during the study period and established the efficacy of amaranth sorghum grains product in rehabilitating MAM children.

\section{Methodology}

\section{Study design}

A cluster randomized controlled trial was used to test the product's efficacy in treating MAM children.

\section{Study area}

This was Kiandutu, the largest slum in Thika District, Kenya. "The estimated prevalence of stunting and underweight are highest among low income groups" $[10,11]$. Kiandutu, an area of low socioeconomic status was selected due to its likelihood of having a high prevalence of malnutrition among children.

Correspondence to: Okoth JK, Department of Food Science and Technology, Jomo Kenyatta University of Agriculture and Technology, Nairobi, Kenya, Tel: 254714408057/254733950524; E-mail: judithokoth@agr.jkuat.ac.ke/ kanensi@gmail.com

Key words: Kenya, malnutrition, efficacy, nutrition

Received: March 08, 2017; Accepted: April 10, 2017; Published: April 14, 2017 


\section{Randomization}

Seven sections in Kiandutu were randomized into either Treatment Group (TG) or Control groups (CG). Sections rather than children were randomized to prevent cross-contamination of information and experiences by placing neighbors in different groups. Randomization ensured that subjects on different treatments were comparable with respect to baseline characteristics, as well as known and unknown risk factors. This reduced the possibility of confounding which could occur in analytical studies.

\section{Recruitment of study participants and blinding of the randomization process}

MAM children were identified daily by the investigator assisted by the nursing officer and the nutrition officer in-charge of Kiandutu health centre (KHC), at Kiandutu slums. The study purpose was explained to the sister in-charge and the nutritionist at KHC, the research assistants, the nutrition educators and mothers of eligible children without revealing the study hypotheses. They were told the research aimed to provide food and nutrition education to mothers with MAM children. Mothers were then recruited upon their informed written consent and followed to their homes.

\section{Target population}

These were MAM children aged 6 to 23 months. At the time of the study, the Kenya Demographic Health Survey of 2008-2009 indicated that, the highest rates of malnutrition are experienced by children in this age category [12].

\section{Inclusion criteria}

- Children between the age of 6 to 23 months

- Children who were already on complementary feeding

- Children with moderate acute malnutrition (MAM) (weight -for -height $\mathrm{Z}$ scores less than -2 to greater than -3 based on WHO Child Growth Standards, 2006)

- Children with mothers/parents who were willing to participate in the study

\section{Exclusion criteria}

- Children with severe acute malnutrition (weight -for -height $\mathrm{Z}$ scores less than $-3 \mathrm{Z}$ scores and above $-2 \mathrm{Z}$ scores). The SAM children were referred to $\mathrm{KHC}$

- Children who were well nourished (weight-for-height Z-scores greater than -2 and less than $+2 \mathrm{Z}$ scores for the well nourished)

- Children whose parents did not intend to live in Kiandutu slums for a period of at least 6 months at the time of recruitment into the study

- Children whose parents or caretakers did not allow home visits

- Children who were obtaining nutrition support from elsewhere

\section{Sampling techniques and sample size determination}

According to KDHS (2008-2009), in urban areas in Kenya 12.6\% of children under five years were underweight, $4.6 \%$ were wasted while $21.6 \%$ were stunted. So, an event rate of $20.0 \%$ was estimated in the controls; a $7.4 \%$ adjustment was made to cover the geographical and resource availability due to differences in the growth of towns. Then an estimate of $2.5 \%$ event rate in the TG was made based on absolute change (an absolute reduction of $17.5 \%$ in the rate of acute malnutrition) [13]. The sample size was calculated using a formula by Donner [14] where n per group was;

$$
\begin{aligned}
& \mathrm{n}=2 \mathrm{pq}\left(\mathrm{z}_{\alpha}+\mathrm{z}_{\beta}\right)^{2} /\left(\mathrm{p}_{1}-\mathrm{p}_{0}\right)^{2} \\
& \text { where, } \mathrm{p}=1 / 2\left(\mathrm{p}_{1}+\mathrm{p}_{0}\right) \\
& \mathrm{q}=1-\mathrm{p},
\end{aligned}
$$

$p_{1}=$ event rate in the controls and $p_{0}=$ event rate in the treatment group.

Corresponding to $\alpha=0.05$ (two sided) and $\beta=0.20, z_{\alpha}=1.96$ and $\mathrm{z}_{\beta}=0.84$.

Therefore, the required sample size was 50 subjects per study group. To cater for attrition, the sample size was inflated by $46 \%$ so that 73 children were recruited per group.

\section{Description of the intervention after baseline done for six months}

Mothers of children in the CG received nutrition education and $2 \mathrm{~kg}$ of flour made from pre-cooked maize and sorghum grains (Figure 1). A composite of maize and sorghum flours porridge is a common complementary food in Kenya. The main focus of the nutrition education was; the importance of timely introduction of complementary feeding at the age of 6 months, diet diversity, frequency of feeding and appropriate hygiene practices in the preparation and storage of complementary foods $[15,16]$. The first nutrition education session was conducted after the baseline interview on individual basis (Figure 1) and included a demonstration on the preparation of porridge using maize sorghum flour. Subsequent nutrition education sessions were given on a monthly basis for emphasis. In addition, information on the quantity and frequency at which it should be given were re-emphasized. The mothers were advised to feed the children on $600 \mathrm{ml}$ ( 2 cups, ratio of flour to water 1:8) of porridge made from maize sorghum flour on a daily basis so that the amounts given were similar to given to the TG. This would give the children $266.8 \mathrm{kcal}$ of energy per day. During these sessions, mothers were encouraged to raise any concerns on infant feeding including any challenges related to the use of maize sorghum porridge for their children. The maize sorghum flour $(2 \mathrm{~kg})$ was distributed bi-weekly every month for six months.

Mothers of children in TG group received extruded amaranth sorghum grains flour at the time of recruitment into the study and a demonstration on preparation of the porridge. The amaranth sorghum grains flour 's efficacy in rehabilitating MAM was being tested. Okoth et al. [17] reported that amaranth sorghum grains porridge is nutrient dense. It was accompanied with nutrition education; whose content was similar to that given to the mothers of children in the CG. Mothers with children aged 12 to 23 months were asked to feed their children $600 \mathrm{ml}$ of porridge ( 2 cups of $300 \mathrm{ml}$ with flour to water ratio of 1:2) on a daily basis. This would give the children $1000 \mathrm{kcal}$ of energy and 28.8 $\mathrm{g}$ of protein per day. Mothers with children aged 6 to 12 months were asked to feed their children $700 \mathrm{ml}$ of porridge ( 3 cups of $233.3 \mathrm{ml}$ with flour to water ratio of 1:4) daily. This would give children $700 \mathrm{kcal}$ of energy and $20.2 \mathrm{~g}$ of protein. The quantities of porridge to be given were based on the recommended daily allowance for energy based on age group. The food ( $2 \mathrm{kgs}$ ) was distributed bi-weekly (Figure 1) for six months.

\section{Determination of study outcome (Nutrition status)}

Anthropometric measurements were taken using mid upper arm circumference tapes (MUAC), Salter scale (weight) and length/height measuring board (Length/height). 


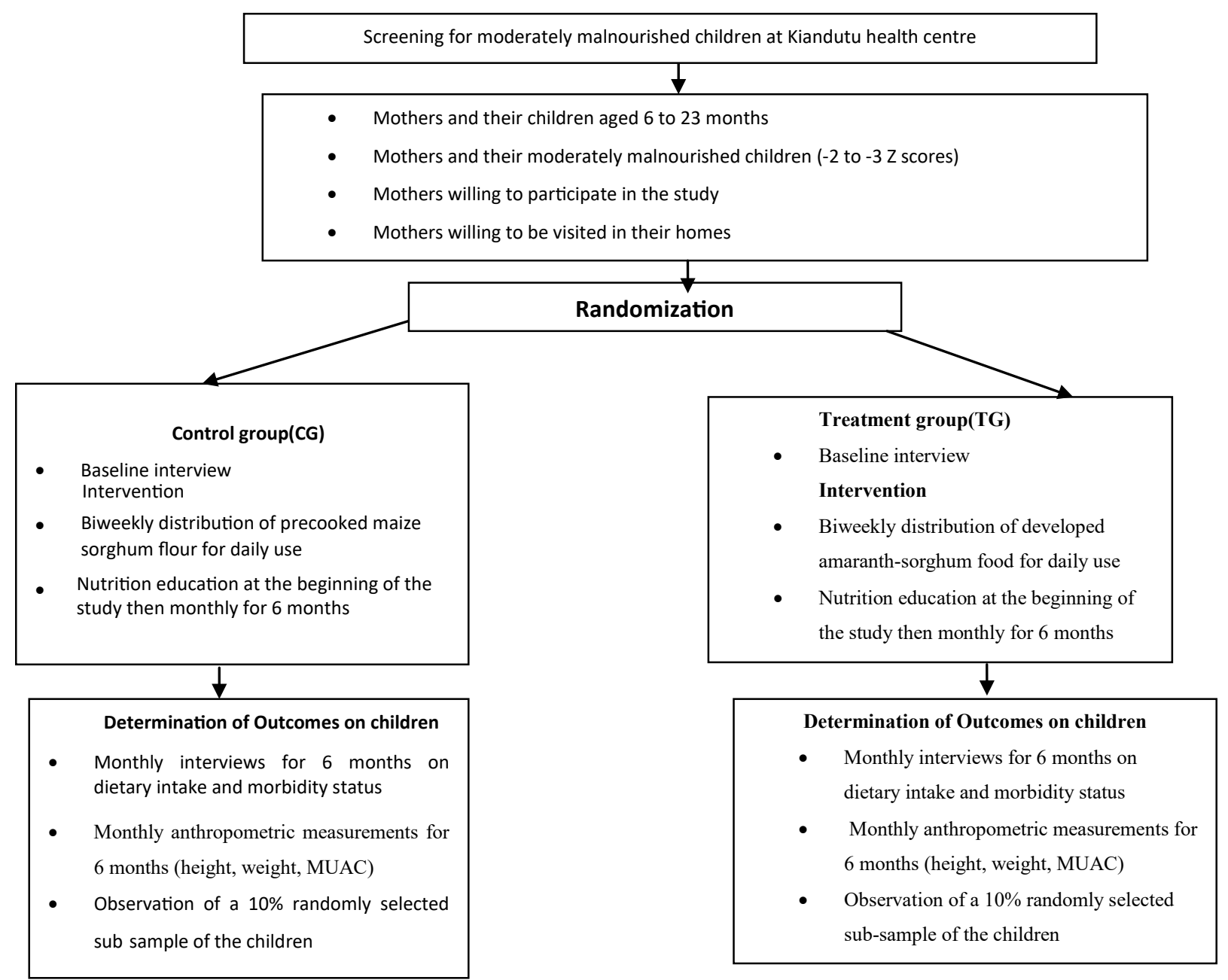

Figure 1. Flowchart of study design and treatments for the study groups.

\section{Methods for collection of data}

\section{Interviews}

A total of seven interviews were administered, at baseline and subsequent monthly interviews for 6 months, to mothers/caregivers in the study groups as shown in Figure 2. Interviews were conducted at the maternal home to provide uninterrupted privacy. The interviews lasted 20 to 30 minutes. Working mothers were visited over weekends. Five questionnaires were developed and validated to collect information from mothers/caregivers. They were designed to solicit information as follows:

- Baseline questionnaires were administered to collect children `s biodata, demo socio-economic characteristics of caregivers and households, morbidity status (sick or not in the previous two weeks) and dietary intake.

- Subsequent monthly interviews on children's morbidity status and dietary intake were done.

- Monthly anthropometric measurements were also taken.

\section{Anthropometry}

Children's MUAC, weight and length were taken as described by FSAU, 2003. Weight and length measurements were used to determine nutritional status based on weight-for-height index. Anthropometric measurements were taken at baseline and on a monthly basis for six months (Figures 1). Length/height and weight of the children under study were taken using length/height measuring board and a Salter scale respectively. Weight and length were each taken thrice to the nearest $0.1 \mathrm{~kg}$ and $0.1 \mathrm{~cm}$, respectively and the average taken as the final reading. Recumbent length was taken for children less than two years or those whose length was shorter than $85 \mathrm{~cm}$. For those whose length was greater than $85 \mathrm{~cm}$, height was measured (FSAU, 2003). This was the cut off at the time the study was undertaken. The age was determined from Child Health Cards.

\section{Pretesting of the study instruments}

The data collection instruments were pre-tested prior to the research to ascertain their feasibility, reliability, validity and accuracy using test retest method. This was done at Gachagi slums, in Makongeni, Kiambu County because it has similar characteristics to Kiandutu slums. Tests on the sensitivity, clarity and length of the questions were done. The duration of the interview and study procedures were also tested and modified accordingly. The weighing scales, length boards and MUAC tapes were also tested. The respondents used for the pretesting were 16, ( $10 \%$ of sample size). 


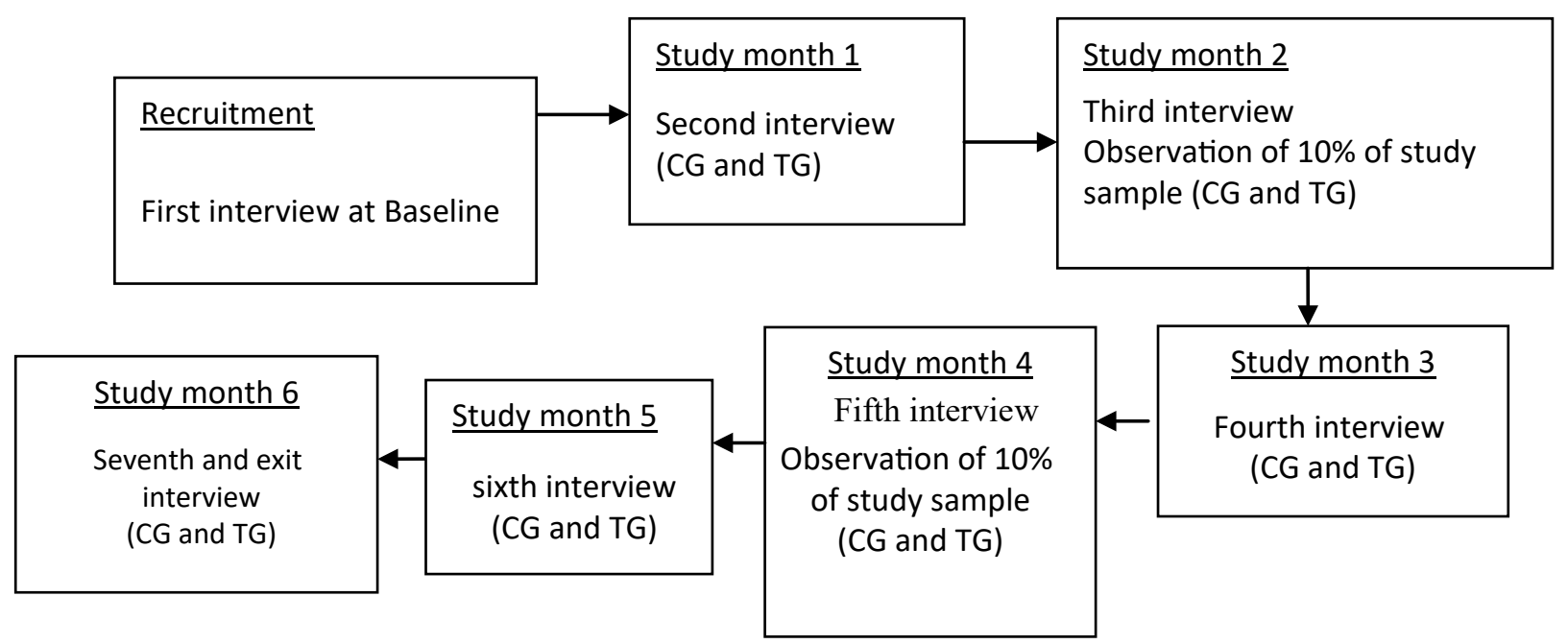

Figure 2. Schedule for Interviews and Observations in the two study groups.

\section{Study variables}

Dependent and independent variables: Nutritional status by wasting was a primary outcome. Nutritional status was measured by the proportion of children in each group who were wasted (weightfor -height $\mathrm{Z}$ scores and MUAC). Nutrition status was a dependent variable while the food given was the independent variable.

Data analysis: SPSS was used for statistical analysis. Chi-square and relative risk ratio were used to compare TG and CG. Weight-for-height and MUAC were used to give the children's nutritional status. WHO Child Growth Standards (2006) were used to interpret the nutritional status of the children. In Kenya, it was the one in use at the time of the study. Children below $-2 Z$ scores and above $-3 Z$ scores weight-forheight indices were considered moderately wasted while those below $-3 Z$ scores were considered to be severely wasted and those above $+2 Z$ scores were considered overweight while less $+2 \mathrm{Z}$ scores and greater than $-2 \mathrm{Z}$ scores were considered normal.

Logistical and ethical considerations: Authority to conduct the research was given by Kenyatta University`s Graduate school, National Commission of Science, Technology and Innovation (National Council of Science and Technology at the time the study), Thika district hospital and Kiandutu health centre. Ethical clearance was given by Kenya Medical Research Institute (KEMRI), National Ethical Review (SSC no 127). Participant's parents' written informed consent was solicited before enrolment into the study by written signature or thumb print. All participants' identification and all conversation information were regarded as confidential and used only for study purposes.

\section{Results and discussion}

\section{Recruitment process and trial profile of subjects}

A total of 147 children out of the 498 screened during February 2011 to March 2011 who met the selection criteria were invited to participate in the study. Of these, 146 (99.3\%) mothers consented to participate in the study (Figure 3). Out of the study population randomized, $38.3 \%$ of children in the TG and $56.2 \%$ in CG dropped out of the study as summarized in Figure 3.

\section{Key baseline characteristics of the study population}

Baseline characteristics of the two groups (TG and CG) were comparable: no significant differences found in age and sex distribution

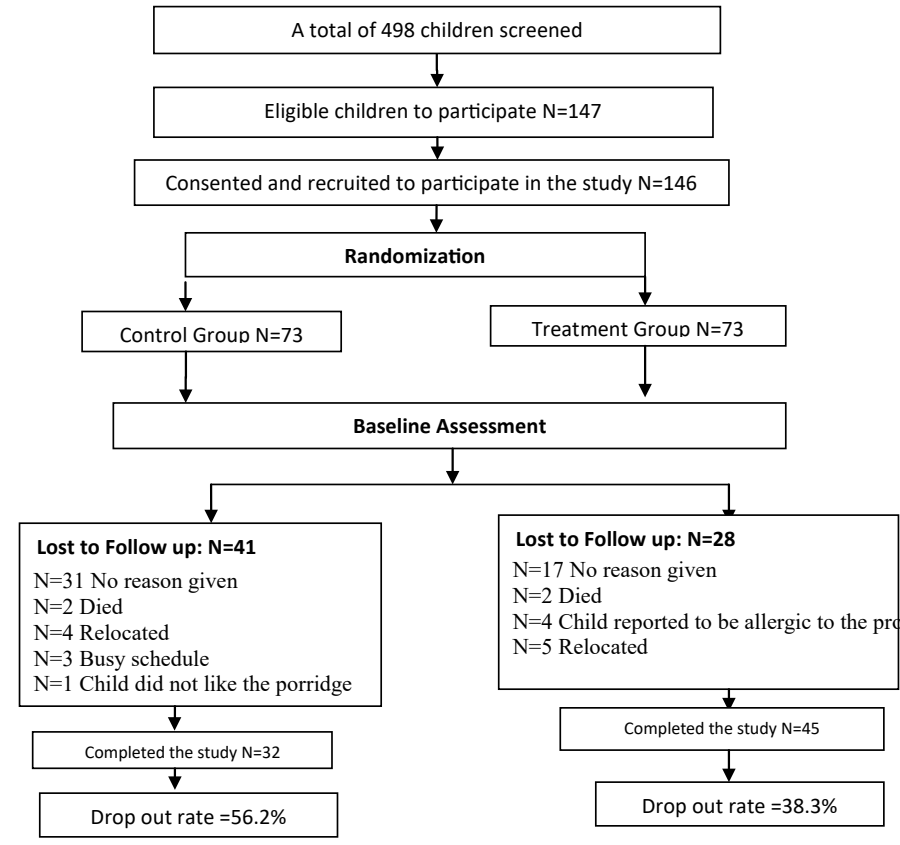

Figure 3. Schematic representation of the recruitment process of study participants.

of children, their caregivers and household heads, socioeconomic characteristics of households ( $p>0.05$ (Tables 1 and 2). There was also no significant difference between the groups $(\mathrm{p}>0.05)$ in morbidity status in the previous two weeks (Table 3 ). Diet intake data is not given here. However, there was no significant difference between the two groups ( $\mathrm{p}>0.05)$.

\section{Nutritional status of children by study groups at baseline}

Majority (74\%) of children were moderately underweight, more than half (53.4\%) were moderately wasted and $52.1 \%$ were moderately stunted; with $\mathrm{Z}$ scores ranging from less than -2 and more than -3 (Table 4). The rest were mildly wasted, underweight and stunted (-2 to $-1 \mathrm{Z}$ scores; WHO, 2006). All the children in the study had MUAC ranging from $11.5 \mathrm{~cm}$ to $12.5 \mathrm{~cm}$ denoting moderate malnutrition. At baseline, there was no significant difference $(p>0.05)$ in the nutritional status of children in the two study groups implying that the two groups could be compared. 
Okoth JK (2017) Efficacy of amaranth sorghum grains porridge in rehabilitating moderately acute malnourished children in a low-resource setting in Kenya: A randomized controlled trial

Table 1. Comparison of demographic characteristics of the study children and the study population.

\begin{tabular}{|c|c|c|c|c|c|}
\hline Characteristics & & Total $=146$ & TG N=73 & CG N=73 & $\begin{array}{c}\text { Chi-square and } t \text { test (p } \\
\text { value) }\end{array}$ \\
\hline \multirow{3}{*}{ Child age (in months) } & Mean (SD) & $11.9(4.6)$ & $12.1(5.0)$ & $11.6(4.2)$ & \multirow{3}{*}{$0.761(0.448)$} \\
\hline & $6-11$ & $85(58.2)$ & $43(58.9)$ & $42(57.5)$ & \\
\hline & $12-23$ & $61(41.8)$ & $30(41.1)$ & $31(42.5)$ & \\
\hline \multirow{2}{*}{ Sex of children } & Male & $70(47.9)$ & $33(45.2)$ & $37(50.7)$ & \multirow{2}{*}{$0.439(0.508)$} \\
\hline & Female & $76(52.1)$ & $40(54.8)$ & $36(49.3)$ & \\
\hline Caretakers age (in years) & Mean (SD) & $25.5(5.4)$ & $25.7(5.9)$ & $25.3(4.9)$ & $0.456(0.650)$ \\
\hline Household head age (in years) & Mean (SD) & $30.9(7.3)$ & $31.5(8.6)$ & $30.4(5.8)$ & $0.892(0.374)$ \\
\hline \multirow{3}{*}{ Caregiver and child relationship } & Mother & $143(97.9)$ & $73(100.0)$ & $70(95.9)$ & \multirow{3}{*}{$3.063(0.216)$} \\
\hline & Aunt & $2(1.4)$ & $0(0.0)$ & $2(2.7)$ & \\
\hline & Grandmother & $1(0.7)$ & $0(0.0)$ & $1(1.4)$ & \\
\hline \multirow{2}{*}{ Sex of the household head } & Male & $114(78.1)$ & $54(74)$ & $60(82.2)$ & \multirow{2}{*}{$0.971(0.324)$} \\
\hline & Female & $32(21.9)$ & $19(26.0)$ & $13(17.8)$ & \\
\hline \multirow{4}{*}{ Marital status of the caregiver } & Single & $20(13.7)$ & $8(11.0)$ & $12(16.4)$ & \multirow{4}{*}{$1.228(0.746)$} \\
\hline & Married & $114(78.1)$ & $57(78.1)$ & $58(79.5)$ & \\
\hline & Separated & $9(6.2)$ & $6(8.2)$ & $2(2.7)$ & \\
\hline & Widowed & $3(2.1)$ & $2(2.7)$ & $1(1.4)$ & \\
\hline \multirow{5}{*}{ Household size } & Mean (SD) & $4.4(1.8)$ & $4.5(2.1)$ & $4.3(1.5)$ & \multirow{5}{*}{$0.500(0.618)$} \\
\hline & $1-2$ & $8(5.47)$ & $6(8.2)$ & $2(27)$ & \\
\hline & $3-4$ & $83(56.8)$ & $40(54.8)$ & $43(58.9)$ & \\
\hline & $5-6$ & $44(30.1)$ & $21(28.8)$ & $23(31.5)$ & \\
\hline & 7 and more & $11(7.6)$ & $6(8.2)$ & $5(6.8)$ & \\
\hline
\end{tabular}

Table 2. Key socioeconomic characteristics of caregivers and household heads by study groups.

\begin{tabular}{|c|c|c|c|c|c|}
\hline \multicolumn{2}{|c|}{ Socio-economic characteristics } & \multirow{2}{*}{$\begin{array}{c}\text { Total } \\
\mathbf{N = 1 4 6 ( \% )}\end{array}$} & \multirow{2}{*}{$\begin{array}{c}\text { TGN=73 } \\
\text { n (\%) } \\
6(8.2)\end{array}$} & \multirow{2}{*}{$\begin{array}{c}\text { CGN=73 } \\
\text { n (\%) } \\
0(0.0)\end{array}$} & \multirow{2}{*}{$\begin{array}{c}\begin{array}{c}\text { Chi-square } \\
\text { (p-value) }\end{array} \\
7.229(0.204)\end{array}$} \\
\hline \multirow{4}{*}{ Caregivers'highest educational level } & No formal education & & & & \\
\hline & Primary education & $113(77.4)$ & $54(73.9)$ & $59(80.8)$ & \\
\hline & Secondary education & $26(17.8)$ & $13(17.8)$ & $13(17.8)$ & \\
\hline & College/University & $1(0.69)$ & $0(0.0)$ & $1(1.4)$ & \\
\hline \multirow{4}{*}{ Household head education level } & No formal education & $5(3.4)$ & $5(6.8)$ & $0(0)$ & $9.668(0.085)$ \\
\hline & Primary education & $103(70.5)$ & $46(63)$ & $58(79.4)$ & \\
\hline & Secondary education & $3(24)$ & $20(27.4)$ & $14(19.2)$ & \\
\hline & College/University & $3(2.1)$ & $2(2.7)$ & $1(1.4)$ & \\
\hline \multirow{5}{*}{ Occupation of caregiver } & Unemployed & $21(14.4)$ & $11(15.1)$ & $10(13.7)$ & $3.233(0.520)$ \\
\hline & Casual Employment & $32(21.9)$ & $17(23.3)$ & $15(20.5)$ & \\
\hline & Housewife & $60(41.1)$ & $33(45.2)$ & $27(37)$ & \\
\hline & Business person & $25(17.1)$ & $9(12.3)$ & $16(21.9)$ & \\
\hline & Other & $8(5.5)$ & $3(4.1)$ & $5(6.8)$ & \\
\hline \multirow{4}{*}{ Employment status of household head } & Not Formally Employed & $27(18.5)$ & $11(15.1)$ & $16(21.9)$ & $6.587(0.086)$ \\
\hline & Temporary Employed & $104(71.2)$ & $50(68.5)$ & $55(75.3)$ & \\
\hline & Permanently Employed & $9(6.2)$ & $8(11)$ & $1(1.4)$ & \\
\hline & Other & $6(4.1)$ & $4(5.5)$ & $1(1.4)$ & \\
\hline \multirow{9}{*}{ Occupation of household head } & Herding & $2(1.3)$ & 0 & $2(2.7)$ & \\
\hline & Artisan (Juakali) & $26(17.8)$ & $17(23.3)$ & $9(12.3)$ & \\
\hline & Teacher & $1(0.7)$ & 0 & $1(1.3)$ & \\
\hline & Business & $34(23.3)$ & 14(19.2) & $20(27.4)$ & \\
\hline & Casual labourer & $55(37.7)$ & $25(34.2)$ & $30(41.1)$ & \\
\hline & Watchman & $4(2.7)$ & $3(4.1)$ & $1(1.4)$ & \\
\hline & Cyclist (Boda boda) & $11(7.5)$ & $9(12.3)$ & $2(2.7)$ & \\
\hline & Unemployed & $5(3.4)$ & $2(2.7)$ & $3(4)$ & \\
\hline & Others & $8(5.5)$ & $4(5.5)$ & $4(5.5)$ & \\
\hline
\end{tabular}

\section{Results following the intervention}

Trends in morbidity prevalence and nutrition status among children during the study period

There were no significant differences in some key demosocioeconomic characteristics of the households whose children completed the study and those who dropped (Table 5). Such differences may reflect adversely on the representation of the study population. Also, there was no change in diet intake during the period of study. The number of children who had been sick in the previous 2 weeks was highest at baseline (Figure 4) for both groups. There was, however, a reduction in the morbidity prevalence over the study period for both groups. This agrees with other studies [18-20] that morbidity has a strong correlation with nutritional status because all these 
Okoth JK (2017) Efficacy of amaranth sorghum grains porridge in rehabilitating moderately acute malnourished children in a low-resource setting in Kenya: A randomized controlled trial

Table 3. Comparison of baseline morbidity prevalence for children by study groups.

\begin{tabular}{|c|c|c|c|c|c|}
\hline \multicolumn{2}{|c|}{} & $\begin{array}{c}\text { Total } \\
\text { N=146 }\end{array}$ & $\begin{array}{c}\text { TG N=73 } \\
\text { n(\%) }\end{array}$ & $\begin{array}{c}\text { CG N=73 } \\
\text { n(\%) }\end{array}$ & $\begin{array}{c}\text { Chi square } \\
\text { (p-value) }\end{array}$ \\
\hline \multirow{2}{*}{$\begin{array}{c}\text { Children sick in the } \\
\text { previous two weeks }\end{array}$} & Yes & $90(61.6)$ & $45(61.6)$ & $45(61.6)$ & $0.028(0.866)$ \\
\hline \multirow{2}{*}{$\begin{array}{c}\text { Duration of time } \\
\text { taken to seek help }\end{array}$} & No & $56(38.4)$ & $28(38.4)$ & $28(38.4)$ & \\
\cline { 2 - 6 } & Afthin 24 hours & $29(43.3)$ & $16(50)$ & $13(37.1)$ & $1.198(0.275)$ \\
\hline
\end{tabular}

Table 4. Baseline anthropometric measurements and nutritional status of children by study groups.

\begin{tabular}{|c|c|c|c|c|c|}
\hline Children characteristics & $\begin{array}{l}\text { Nutrition } \\
\text { status } \\
\text { Indicator }\end{array}$ & $\begin{array}{c}\mathrm{N}=146 \\
\mathrm{n}(\%)\end{array}$ & $\begin{array}{c}\mathrm{CG} \\
\mathrm{N}=73 \\
\mathrm{n}(\%)\end{array}$ & $\begin{array}{c}\mathrm{TG} \mathrm{N}=73 \\
\mathrm{n}(\%)\end{array}$ & $\begin{array}{c}\text { Chi square } \\
\text { (p-value) }\end{array}$ \\
\hline MUAC $(11.5-12.5 \mathrm{~cm})$ & \multirow{2}{*}{ WAZ } & $146(100)$ & $73(100)$ & $73(100)$ & $20.9(0.692)$ \\
\hline Underweight $(<-2 \mathrm{Z}$ scores $)$ & & $108(74)$ & $57(78.1)$ & $51(69.9)$ & $286(0.423)$ \\
\hline Wasted ( $<-2 \mathrm{Z}$ scores) & WHZ & $78(53.4)$ & $39(53.4)$ & $39(53.4)$ & $283.9(0.241)$ \\
\hline Stunted ( $<-2 \mathrm{Z}$ scores) & HAZ & $76(52.1)$ & $41(56.2)$ & $35(47.9)$ & $285(0.456)$ \\
\hline
\end{tabular}

Table 5. Comparison of some key demographic and socioeconomic characteristics of children lost to follow up and those who completed the study.

\begin{tabular}{|c|c|c|c|}
\hline Characteristics & $\begin{array}{l}\text { Completed the study } \\
(\mathrm{N}=77)\end{array}$ & $\begin{array}{l}\text { Lost to follow up } \\
\qquad(\mathrm{N}=70)\end{array}$ & $\begin{array}{c}\text { Chi-sq and t-test } \\
\text { p-value }\end{array}$ \\
\hline \multicolumn{4}{|c|}{ Sex } \\
\hline Male & $41(53.2 \%)$ & $34(48.6 \%)$ & \multirow{2}{*}{0.311} \\
\hline Female & $36(46.8 \%)$ & $36(51.4 \%)$ & \\
\hline \multicolumn{4}{|c|}{ Household size } \\
\hline Mean (SD) & $4.66(2.1)$ & $4.1(1.5)$ & 0.284 \\
\hline \multicolumn{4}{|c|}{ Caretakers'highest educational level } \\
\hline Not attended school & $4(5.2)$ & $2(2.9)$ & \multirow{4}{*}{0.423} \\
\hline Primary school & $59(84)$ & $55(78.6)$ & \\
\hline Secondary school & $10(12.9)$ & $16(122.9)$ & \\
\hline $\begin{array}{l}\text { College and } \\
\text { university }\end{array}$ & $11(1.3)$ & $0(0)$ & \\
\hline \multicolumn{4}{|c|}{ Occupation of caregiver } \\
\hline Not employed & $8(10.3)$ & 13(18.6) & \multirow{5}{*}{0.588} \\
\hline Casual employment & $18(23.4)$ & $14(23.4)$ & \\
\hline Housewife & $36(46.7)$ & $26(37)$ & \\
\hline Business & $11(14.2)$ & $12(17.1)$ & \\
\hline Others & $4(5.2)$. & $5(7.1)$ & \\
\hline
\end{tabular}

children were malnourished at baseline. In this study, the prevalence of morbidity among the children did not differ significantly across the study groups. This could be attributed to the two groups having similar nutrition education given during the study. The effect of morbidity on nutritional status depends on the severity and duration of infection, care provided and feeding during illness and convalescence [20,21].

\section{The comparison of trends in nutritional status between the study groups}

At 1 month, the proportion of children who were wasted were $38.9 \%$ and $32.6 \%$ in the CG and TG respectively. The proportion of wasted children in the TG reduced as given in Figure 5 from 32.7\% at month 1 to $13.3 \%$ after month 6 . In the CG the proportion of wasted children reduced from $39 \%$ at month 1 to $36.7 \%$ at month 6 . There was a significantly higher reduction in the proportion of wasted children in the TG compared to the CG after month $5(\mathrm{p}=0.028)$ and month $6(\mathrm{p}=0.023)$.

\section{Impact of the intervention on the study population}

At Month 1, there was no significant difference in the percentage of children who were malnourished by weight for height $\mathrm{Z}$ scores in the CG and TG (Relative Risk (RR): 1.07 [95\% CI: 0.83-1.38; p=0.606 (Table 6). The same trend was observed from months 2 to 4 despite the proportion of the malnourished children being higher in the CG. In contrast, at month 5 and 6 , significantly higher percentages of children in the CG were wasted compared to those in the TG. At month 5, the children in the TG were 1.3 times (RR: 1.35 [95\% CI: 1.03-1.77; $\mathrm{p}=0.030$ ) more likely to be well nourished than their counterparts in the CG. Similarly, at month 6 , children in the TG were 2 times more likely to be well nourished than those in the CG (RR; 2.23 [95\% CI: 1.37-3.61]; $\mathrm{p}<0.001)$. At Month 1 , there was no significant difference in the percentage of the children who were malnourished by MUAC in the CG and TG (Relative Risk (RR): 0.96[95\% CI: 0.56-1.63; p=0.884) (Table 7). The same trend was observed at months 2 to 4 . On the other hand, at months 5 and 6, higher percentages of children in the CG were wasted compared to those in the TG. At month 5 , the children in the TG were 2 times (RR: 2.06 [95\% CI: 1.28-3.33; p<0.003) more likely to be well nourished than their counterparts in the CG. Also at month 6, children in the TG were 2 times more likely to be well nourished than those in the CG (RR; 2.32[95\% CI: 1.37-3.91]; $\mathrm{p}=0.001$ ).

At baseline, all the children were malnourished based on MUAC measurements. The amaranth-sorghum grains product made a significant impact by reducing the level of malnutrition in children. At

Table 6. Impact of the intervention on wasting (weight-for-height $Z$ Scores) among the children by study group over time.

\begin{tabular}{|c|c|c|c|}
\hline Time of study & $\begin{array}{c}\text { CG Relative } \\
\text { Risk }=1\end{array}$ & TG Relative Risk (RR) & p value RR \\
\hline \multirow{2}{*}{ Month 1 } & $\mathrm{N}=50$ & $\mathrm{~N}=52$ & \\
& $38.9 \%$ & $32.7 \% ; \mathrm{RR}=1.07[(95 \% \mathrm{CI}: 0.83-1.36)]$ & 0.411 \\
Month 2 & $\mathrm{N}=42$ & $\mathrm{~N}=50$ & \\
& $28.6 \%$ & $24.0 \% ; \mathrm{RR}=1.06[(95 \% \mathrm{CI}: 0.83-1.36)]$ & 0.622 \\
Month 3 & $\mathrm{N}=41$ & $\mathrm{~N}=48$ & \\
& $34.1 \%$ & $20.0 \% ; \mathrm{RR}=1.26[(95 \% \mathrm{CI}: 0.98-1.63)]$ & 0.069 \\
Month 4 & $\mathrm{N}=38$ & $\mathrm{~N}=46$ & \\
& $35.3 \%$ & $17.9 \% ; \mathrm{RR}=1.93[(95 \% \mathrm{CI}: 0.94-1.51)]$ & 0.44 \\
Month 5 & $\mathrm{N}=34$ & $\mathrm{~N}=45$ & \\
& $35.3 \%$ & $12.8 \% ; \mathrm{RR}=1.35[(95 \% \mathrm{CI}: 1.03-1.77)]$ & $0.030^{*}$ \\
Month 6 & $\mathrm{N}=29$ & $\mathrm{~N}=45$ & \\
& $62.1 \%$ & $15.6 \% ; \mathrm{RR}=2.23[(95 \% \mathrm{CI}: 37-3.61)]$ & $<0.001 * *$ \\
\hline
\end{tabular}

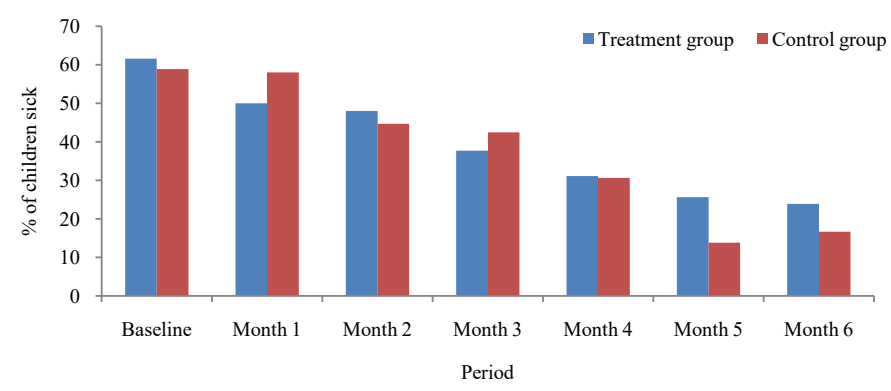

Figure 4. Monthly trend of morbidity prevalence during the study period.

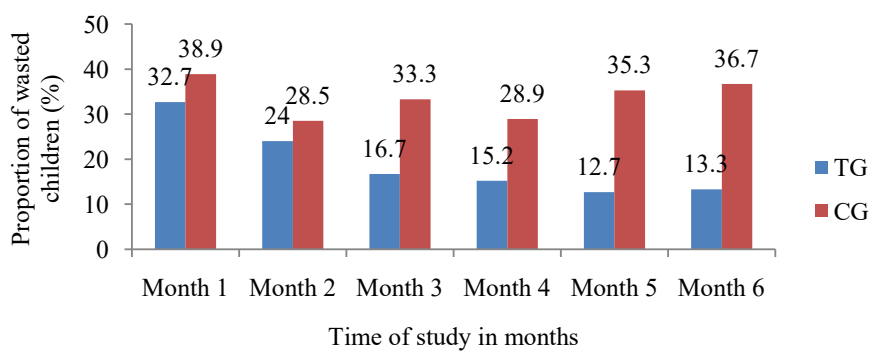

Figure 5. Trends in wasting levels for children during the study period as given by weight for height $\mathrm{z}$ scores. 
Okoth JK (2017) Efficacy of amaranth sorghum grains porridge in rehabilitating moderately acute malnourished children in a low-resource setting in Kenya: A randomized controlled trial

Table 7. Impact of the intervention on the nutritional status (wasting-MUAC) of children by study group overtime.

\begin{tabular}{|c|c|c|c|}
\hline Time of study & $\begin{array}{c}\text { CG Relative } \\
\text { Risk }=1\end{array}$ & TG Relative Risk (RR) & p value RR \\
\hline \multirow{2}{*}{ Month1 } & $\mathrm{N}=50$ & $\mathrm{~N}=52$ & \\
& $64.0 \%$ & $65.3 \% ; \mathrm{RR}=0.96[(95 \% \mathrm{CI}: 0.56-1.63)$ & 0.884 \\
Month 2 & $\mathrm{N}=42$ & $\mathrm{~N}=50$ & \\
& $59.5 \%$ & $56.0 \% ; \mathrm{RR}=1.39[(95 \% \mathrm{CI}: 0.88-2.21)]$ & 0.156 \\
Month 3 & $\mathrm{N}=41$ & $\mathrm{~N}=48$ & \\
& $58.5 \%$ & $38.8 \% ; \mathrm{RR}=1.45[(95 \% \mathrm{CI}: 0.96-2.26])$ & 0.073 \\
Month 4 & $\mathrm{N}=38$ & $\mathrm{~N}=46$ & \\
& $51.3 \%$ & $36.4 \% ; \mathrm{RR}=1.31[(95 \% \mathrm{CI}: 0.88-1.93)]$ & 0.185 \\
Month 5 & $\mathrm{N}=34$ & $\mathrm{~N}=45$ & \\
& $63.6 \%$ & $20.0 \% ; \mathrm{RR}=2.06(95 \% \mathrm{CI}: 1.28-3.33)]$ & $<0.003$ \\
Months6 & $\mathrm{N}=29$ & & $\mathrm{~N}=45$ \\
& $65.5 \%$ & $20.0 \% ; \mathrm{RR}=2.32[(95 \% \mathrm{CI}: 1.37-3.91)]$ & $0.001 * *$ \\
\hline
\end{tabular}

month 5 and 6 , the proportion of children in the TG who were well nourished (not wasted) was significantly higher than those in the CG judged by both $\mathrm{Z}$ scores and MUAC. This implies that the amaranthsorghum grains product was effective in rehabilitating MAM children albeit slowly. The recovery time was longer than the WHO and Sphere Standards recommended time of 90 days or less. This could be due to leakage because the study site was food insecure at the time of the study necessitating WFP to give blanket supplementary feeding. Protection ratio was given to minimize this practice. However sharing of the product was not investigated.

At months 5 and 6 of the study, wasting levels by WHZ and MUAC were significantly lower in the TG compared to the CG. The wasting levels reduced by almost half in the TG while for the CG the levels of wasting did not change significantly. These results are in agreement with those of Maoga et al. [22]. Who reported that Children living with HIV and Aids virus consuming amaranth based porridge had a significant reduction $(\mathrm{p}<0.001)$ in wasting levels (pre-and-post intervention wasting levels were $34 \%$ and $21.2 \%$ respectively) [22]. Besides if adopted as a complementary food, amaranth sorghum grain porridge could contribute towards preventing wasting all together.

\section{Conclusions}

The demographic and socioeconomic characteristics of the study population were similar at baseline. The morbidity prevalence was not different for the two study groups during the study period. The amaranth-sorghum grains product improved the nutritional status of the children albeit slowly.

\section{References}

1. Kenya National Bureau of Statistics (KNBS), ICF Macro (2015) Kenya Demographic and Health Survey 2008-09. Calverton, Maryland: KNBS and ICF Macro.

2. Owino V, Amadi, B, Sinkala M, Filteau S, Tomkins A (2008) Complementary feeding practices and nutrient intake from habitual complementary foods of infants and children aged 6-18 months old in Lusaka, Zambia. AJFAND 8(1).
3. Owino V (2010) Why lipid-based ready to use foods (RUF) must be key components of strategiesto manage acute malnutrition in resource poor settings. AJFAND 10(3).

4. Thakwalakwa C, Ashorn P, Phuka J, Bun Cheung Y, Briend A, et al. (2010) A LipidBased Nutrient Supplement but Not Corn-Soy Blend Modestly Increases Weight Gain among 6- to 18-Month-Old Moderately Underweight Children in Rural Malawi. J Nutr 140(11): 2008-2013. [Crossref]

5. Linneman Z, Matilsky D, Ndekha M, Maleta K, Manary MJ (2007) A largescale operational study of home-based therapy with ready-to-use therapeutic food in childhood malnutrition in Malawi. Matern Child Nutr 3(3): 206-215. [Crossref]

6. Alemu J (2008) The African Executive Development. Artsvisval. www.africanexecutive. com/modules/ma accessed 28/04/2008.

7. Yarger L (2008) Amaranth Grain and Vegetable Types. Echo Technnical note. www. echonet.org accessed on 18th July 2012.

8. Macharia-Mutie CW, Kok FJ, Brouwer DI, Mwangi A (2012) Efficacy of amaranth grain (Amaranthus cruentus) on anaemia and iron deficiency in Kenyan pre- school children. PhD Thesis.

9. Africancrops (2007) www.africancropsnet/crops/sorghum/ accessed on 1/12/2007

10. United Nations Children's Fund, World Health Organization, The World Bank (UNICEFWHO-World Bank) (2012) Joint Child Malnutrition Estimates. UNICEF, New York; WHO, Geneva; The World Bank, Washington, DC.

11. World Health Organization (WHO) (2012) Water sanitation and health http://www. who.int/water sanitation health/diseases/malnutrition/ accessed on 16/7/2012.

12. Kenya National Bureau of Statistics (KNBS), ICF Macro (2010) Kenya Demographic and Health Survey 2008-09. Calverton, Maryland: KNBS and ICF Macro.

13. Schulz KF, Grimes DA (2005) Sample size calculations in randomised trials: mandatory and mystical. Lancet 365: 1348-1353. [Crossref]

14. Donner A (1984) Approaches to sample size estimation in the design of clinical trials-a review. Stat Med 3(3): 199-214. [Crossref]

15. WHO (2006) Child growth standards: methods and development: length/height-forage, weight-for-age, weight-for length, weight-for-height and body mass index-for-age. Geneva, Switzerland.

16. WHO (2006) Infant and Young Child Feeding Counselling: An Integrated Course Trainer`s guide.

17. Gupta S, Jamwal DS, Kumar D, Gupta SK (2012) Morbidity among Under Five Children in a Rural Area of Jammu. JK Science 14(2): 85-88.

18. Okoth JK, Ochola S, Gikonyo NK, Makokha A (2016) Development of a nutrient-dense complementary food using amaranth-sorghum grains. J Food Science \& Nutrition.

19. Essendi H, Madise NJ, Martin MK, Jean-Christophe F (2012) Synergistic relationship between child morbidity and malnutrition among the urban poor. Malnutrition and morbidity.

20. Ramachandran P, Gopalan HS (2009) Undernutrition \& risk of infections in preschool children. Indian J Med Res 130: 579-583. [Crossref]

21. Nungo RA, Okoth WM, Mbugua SK (2012) Nutrition Status of Children Under-Five Years in Cassava Consuming Communities in Nambale, Busia of Western Kenya. Food and Nutrition Sciences 3: 796-801.

22. Maoga NW, Kuri EN, Nyambaka H (2012) Nutrient Composition of hypochondriacus amaranth grain and contribution to nutrition status of HIV and AIDS infected children attending Thika District Hospital. PhD Thesis. Kenyatta University, Kenya.

Copyright: (C2017 Okoth JK. This is an open-access article distributed under the terms of the Creative Commons Attribution License, which permits unrestricted use, distribution, and reproduction in any medium, provided the original author and source are credited. 